\title{
27-я Российская конференция по электронной микроскопии 5-я Молодежная школа РКЭМ - 2018
}

А.С. Авилов, д.Ф.-М.Н., ФНИЦ «Кристаллография и фотоника» РАН

УДК 620.187.2 А. Л. Васильев, К.Ф.-М.Н., НИЦ "Курчатовский Институт» avilovanatoly@mail.ru

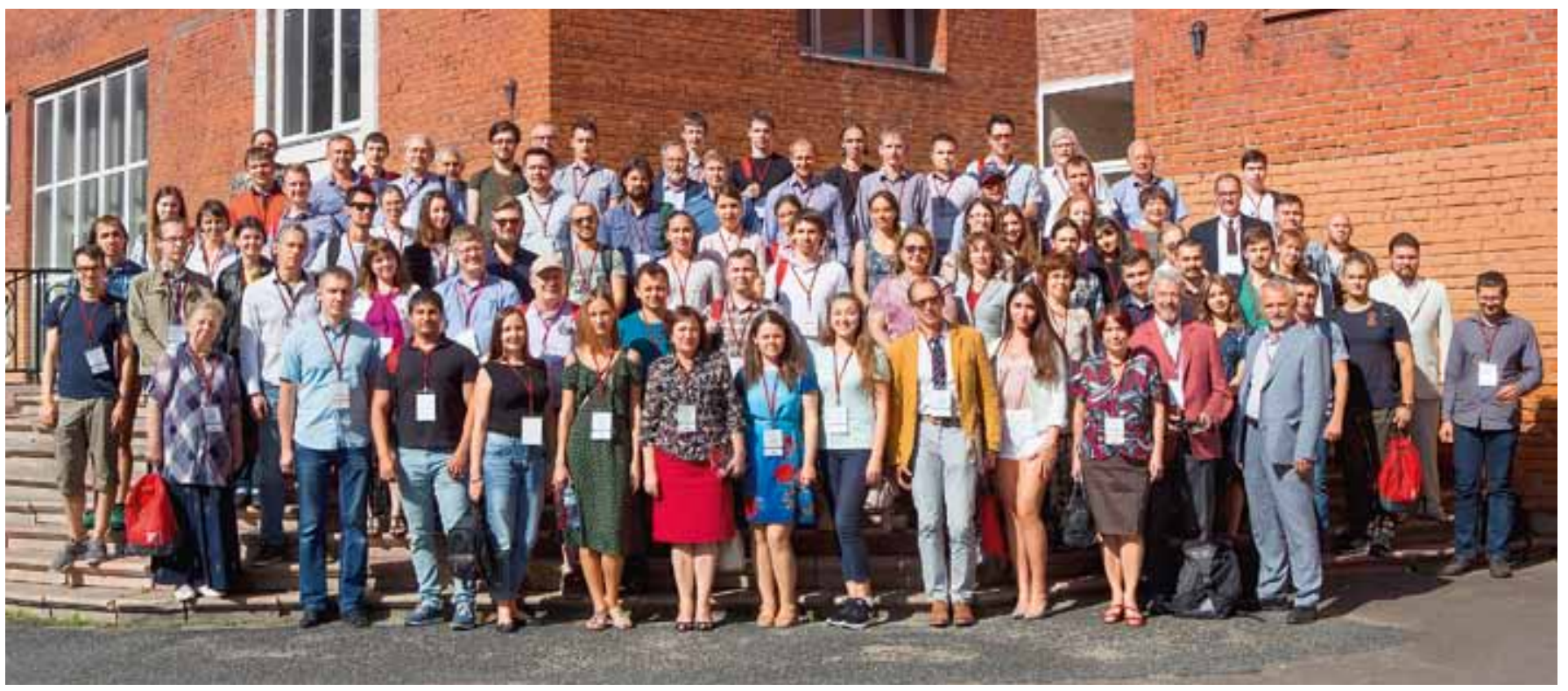

Мы продолжаем рассказ о 27-й Российской конференции по электронной микроскопии (РКЭМ) «Современные методы электронной и зондовой микроскопии в исследованиях органических, неорганических наноструктур и нано-биоматериалов", которая проходила с 26 по 30 августа 2018 года в Черноголовке (Московская область)". В рамках конференции прошла 5-я молодежная школа, в которой приняли участие приглашенные докладчики и их молодые коллеги. На школе прозвучали доклады, посвященные различным методам электронной микроскопии и микроанализа, а также их применению в различных областях: медицине, биологии, материаловедении, в исследованиях предметов культурного наследия и т.д.

Школа молодых ученых «Современные методы электронной и зондовой микроскопии в исследованиях органических, неорганических наноструктур и нано-биоматериалов»- регулярное мероприятие, организуемое по инициативе Научного совета РАН по электронной микроскопии при содействии ФНИЦ "Кристаллография и фотоника" РАН, Института проблем технологии микроэлектроники и особочистых матери-

АНАЛИТИКА, 2018, т. 8, № 6, с. 516-524. алов РАН и НИЦ "Курчатовский институт". В этом году школа проходила при финансовой поддержке Российского фонда фундаментальных исследований. В ее работе приняли участие более 130 ученых из России, Израиля, Беларуси, Франции, Швейцарии, Испании, США и Великобритании. В первой половине каждого дня с обзорными лекциями выступали известные, а во второй половине дня - молодые ученые. Всего 11 докладчиков старше 35 лет и 26 - их младшие коллеги. За лекциями следовали стендовые доклады, которые также представляли молодые. Вечером проходили круглые 
столы, где можно было задать вопросы не только по тематике лекций, но и получить совет по интересующим проблемам. Тезисы докладов на конференции изданы в виде сборника в одном томе, информация о Школе размещена на сайте: https://www.crys.ras.ru/rcem/shkola.

Тематически Школа была разделена на четыре секции:

- Секция 1. Новые методы микроскопии, электронной дифракции и микроанализа;

- Секция 2. Применение микроскопии в биологии и медицине, Крио-ЭМ;

- Секция 3. Микроскопия и сопряженные методы в материаловедении;

- Секция 4. Методы электронной микроскопии и микроанализа в исследовании предметов культурного наследия.

На открытии Школы с приветственным словом выступил председатель программного комитета А. Л. Васильев.

В первый день заслушаны выступления в двух первых секциях, их представили шесть приглашенных (старше 35 лет), из них половина зарубежных специалистов. Докладчики младше 35 лет подготовили 13 сообщений, все на русском языке.

Работу Школы в рамках секции "Новые методы микроскопии, электронной дифракции и микроанализа» открыл доклад "Why TEM?" известного ученого из лаборатории CRISMAT (Caen, Франция) О.И. Лебедева. Выступающий на разных примерах рассказал о последних достижениях в области исследования различных материалов методом просвечивающей электронной микроскопии (ПЭМ). По его мнению метод ПЭМ, в силу рекордного пространственного разрешения в сочетании с данными электронной дифракции и моделирования изображений, занимает уникальное место в развитии современной науки о материалах. Доклад, безусловно, был полезен как состоявшимся, так и молодым, начинающим научным сотрудникам.

Второй доклад «Насколько точны количественные данные энергодисперсионного рентгеновского микроанализа и картирования в нанометровом диапазоне и ниже?" ("How quantitative are (S)TEM EDS microanalysis and mapping at the nanometer scale and beyond?») представлял Филлипп Буфа (Phillippe Buffat) из Междисциплинарного центра электронной микроскопии Политехнической федеральной школы Лозанны. Обсуждались проблемы количественного представления спектральных данных, полученных методом энергодисперсионного рентгеновского микроанализа и картирования за пределами нанометрового диапазона. В настоящий момент сбор данных EDS-спектров и карт распределения элементов с ангстремным разрешением в аналитическом микроскопе является относительно простым этапом, однако при обработке спектров и карт возможно появление артефактов. Необходима подготовка очень тонких образцов, которая остается трудоемкой и сложной задачей для ряда материалов. Резюме доклада: количественная интерпретация все еще страдает от недостатков программного обеспечения; точность или пре- имущества различных подходов, находящихся в разработке, по-прежнему остаются предметом споров.

Доклад Марка Эйндоу из Коннектикутского Университета, США (Институт наук о материалах) под названием «Метод ALCHEMI и его применение в привязке к линии упорядочения" (ALCHEMI and applications of the ordering tie line approach) pacкрыл аспекты применения метода ALCHEMI. ALCHEMI - это метод ПЭМ для измерения локальных особенностей в кристаллах с использованием рентгеновской или электронной спектрометрии. ALCHEMI может дать полезную информацию для решения многих важных проблем, но техника не используется широко, видимо, отчасти потому, что интерпретация данных представляет собой довольно сложную задачу.

В докладе "Наномасштабный химический анализ материалов методом атомно-зондовой томографии" С. В. Рогожкина (ФГБУ ИТЭФ, НИЦ "Курчатовский институт») продемонстрированы возможности реализованной в ИТЭФ атомно-зондовой томографии (АЗТ), в том числе с лазерным испарением. Продвижение этих разработок в значительной мере сопряжено с развитием методик для контроля состояния материалов в субнанометровых масштабах.

Секцию «Микроскопия и сопряженные методы в материаловедении" открыл очень информативный доклад "Эффекты облучения материалов быстрыми тяжелыми ионами", представленный сотрудником НИЦ "Курчатовский институт" А. Е. Волковым. В работе показано, что облучение быстрыми тяжелыми ионами (БТИ, Е > 1 Мэв/ нукл, М>20 а. е. м.) служит основой необычных с точки зрения макроскопических методов новых технологий точечной модификации структуры с уникальным наноразмерным пространственно анизотропным разрешением.

Среди представленных в первый день в рамках этой же секции работ молодых ученых прозвучало несколько выступлений очень высокого уровня. Необходимо отметить доклады И. А. Каратеева "Электронная микроскопия силицидов редкоземельных металлов" и И.Н. Трунькина "Исследование гетероструктур на основе АЗВ5 методами электронной микроскопии". Они представили результаты исследований материалов сравнительно новым методом высокоразрешающей просвечивающей растровой электронной микроскопии с регистрацией электронов, рассеянных на большие углы (в несколько раз больше углов Брегга), что позволяет получать информацию с Z-контрастом (Z - атомный номер). Применение этого метода в совокупности с использованием приборов с коррекцией сферической аберрации дает возможность получать изображения с субангстремным разрешением и эффективно решать задачи определения реальной структуры границ раздела, новых фаз и т. п.

Доклад Н. А. Архаровой (ФНИЦ «Кристаллография и фотоника» РАН) «Высокоразрешающая низковольтная растровая электронная микроскопия пористых полимерных систем» посвящен использованию растровой электронной микроскопии (РЭМ) в исследовании особенностей морфологии 
и 3D-структуры пористых полимерных систем. Полимеры очень чувствительны к облучению электронным пучком, поэтому проведение электронно-микроскопических исследований вызывает радиационные повреждения материала и ставит под сомнение достоверность данных о структуре и морфологии поверхности. Применение низковольтной растровой электронной микроскопии открывает новые возможности в исследовании структурных особенностей пористых полимерных систем.

Комплексные исследования методами электронной микроскопии магнитных периодических металлических систем представлены в докладе Ю. М. Чеснокова (НИЦ "Курчатовский институт») "Исследование микроструктуры магнитных металлических периодических структур". Группа авторов провела комплексные исследования магнитных периодических металлических систем на основе слоев Cr-Gd-Cr-Fe и Dy-Gd методами просвечивающей электронной микроскопии, энергодисперсионного микроанализа, рентгеновской дифракции и резонансной рентгеновской рефлектометрии. Доклад "Приготовление электронномикроскопических образцов поверхностных наноструктур методом фокусированного ионного пучка" Р. Л. Волкова (Национальный исследовательский университет "МИЭТ») был полезен не только начинающим ученым. Представлена методика in-situ lift-out для приготовления тонких фольг методом ФИП. В результате получают образцы с почти плоско-параллельными поверхностями как поперечного, так и планарного сечения. Вместе с тем, при исследовании поверхностных наноструктур, например, гетероструктур или нанопроволок, иногда необходимо, чтобы образец содержал несколько тонких фольг планарного сечения на разном заданном расстоянии от подложки. Они могут быть сформированы путем небольшой вариации методики in-situ lift-out.

Интересные результаты представил сотрудник НИЦ "Курчатовский институт" А. А. Михуткин в докладе "Количественный трехмерный анализ по данным электронно-ионной и конфокальной лазерной сканирующей микроскопии". Закрывали сессию два доклада представителей МИЭТ П. С. Вергелеса "Локализация области формирования LEEBI эффекта в голубых светодиодах с MKя InGaN / GaN" и А. С. Приходько «Метод восстановления волновой функции электрона и его применение для исследования пиролитических углеродных материалов". Выступающие представили примеры исследований методом высокоразрешающей пэм и обсудили особенности обработки изображений с целью восстановления кристаллической структуры объектов.

Второй день школы открывали приглашенные гости с лекциями в рамках секции «Применение микроскопии в биологии и медицине, Крио-ЭМ». Первую лекцию прочитала сотрудница Бирбек колледжа (Университет Лондона, Великобритания) Е. В. Орлова на тему: "Криоэлектронная микроскопия в 21 веке: открытия и вызовы и перспективы" (Cryo electron microscopy in the 21st century: discoveries, challenges, and prospects), второе сообщение "Структурная биология: из XX в XXI век" сделала представительница биологического факультета МгУ О. С. Соколова. Докладчицы рассказали об истории криоэлектронной микроскопии и открытиях в области молекулярной биологии, которые были сделаны этим методом. Достаточно подробно описаны способы обработки изображений, полученных в КриоПЭМ и с помощью соответствующего программного обеспечения. К сожалению, криогенная микроскопия требует достаточно дорогого оборудования, поэтому оснащенность Российских организаций такими приборами пока находится на зачаточном уровне, и квалифицированных кадров, работающих в этой области пока крайне мало.

Приглашенные доклады продолжились тремя выступлениями в рамках секции "Микроскопия и сопряженные методы в материаловедении". В интересном докладе Е. И. Суворовой «Взаимодействие микроорганизмов с неорганическими веществами: образование биогенных наночастиц" показано, как различные микроорганизмы восстанавливают оксиды и соли железа, марганца, хрома, селена, растворенные соединения урана, золота, что, безусловно, имеет фундаментальное и практическое значение.

Сотрудница Университета Бена-Гуриона Негев (Израиль) Л. Меши рассказала о восстановлении структуры комплексных алюминадов с помощью новых методов электронной кристаллографии ("Methodology for structure solution of complex aluminides using novel electron crystallography methods"). Доступно и понятно автор доклада объяснила принципы электронной кристаллографии и описала способы использования различных видов дифракции при определении пространственных групп сложных соединений. Еще один доклад, более материаловедческий, представила сотрудница ВИАМ Е. А. Лукина - «Применение методов аналитической микроскопии в разработке новых материалов авиационного назначения и оптимизации технологии их производства".

Затем прозвучали доклады молодых ученых в рамках секции 2 «Применение микроскопии в биологии и медицине, Крио-ЭМ". Пять молодых участников представили результаты исследований мирового уровня: Ж. А. Афонина "Трехмерная организация эукариотических полирибосом: крио-ЭТ анализ", А. В. Моисеенко А. В. "Применение методов электронной 2D кристаллографии для изучения структуры комплексов белка DPS с ДНК", Т. Н. Баймухаметов "Пространственная структура цитохром с нитритредуктазы из бактерии Thioalkalivibrio nitratireducens, полученная методом криоэлектронной микроскопии", Т. Б. Станишнева-Коновалова "Структура шаперонина бактериофага ОВР по данным криоэлектронной микроскопии", Е.Б.Пичкур "Криоэлектронная микроскопия 70 р рибосомных комплексов с антибиотиками". Работы этих ученых выполнены в НИЦ "Курчатовский институт" и на биологическом факультете МГУ. 
На секции «Методы электронной микроскопии и микроанализа в исследовании предметов культурного наследия" представлен доклад Н. Н. Колобылиной очень высокого уровня в области исторического материаловедения «Исследование объектов культурного наследия комплексными методами электронной микроскопии".

В заключительном цикле из шести лекций секции "Микроскопия и сопряженные методы в материаловедении" выступили А.С. Орехов "Структурная характеризация симплексных мембран на основе полиэлектролитных комплексов хитозана", А. В. Овчаров "Микроструктурный анализ сверхпроводящих лент второго поколения на основе (Gd)BCO с искусственными центрами пиннинга $\mathrm{BaSnO}_{3}$ и $\mathrm{BaZrO}_{3}$ ", Р.А. Камышинский "Криогенная сканирующая электронная микроскопия в исследованиях биосовместимых контейнеров для адресной доставки лекарств", Е. А. Першина "Особенности нанокристаллизации аморфного сплава AІ90Y10 при деформации и термообработке", О.Ю. Рогов «Формирование и исследование хиральных фотонных наноструктур методами растровой электронной микроскопии" и A. В. Заводов "Определение типа LPSO-фаз в магниевом сплаве системы Mg-Zn-Y методами электронной дифракции и высокого разрешения (HRTEM)". Доклады вызвали большой интерес, работы выполнены с использованием новых методов, и уровень результатов способен конкурировать с мировым.

Таким образом, практически все представленные на Школе доклады были насыщены современной ценной научной информацией, использованы самые передовые методы исследования, а результаты открывают широкие перспек-
тивы.Об этом свидетельствует высокая посещаемость лекций: конференц-зал был заполнен участниками Школы.

Во время проведения Школы проходила выставка производителей электронных микроскопов и сопутствующего оборудования. Участники мероприятия познакомились с последними техническими достижениями и новинками, больше узнали о возможностях современных электронных микроскопов. В отдельном помещении был организован Технопарк, где производители представили свои приборы и продемонстрировали их возможности в режиме реального времени. Помимо электронных, были показаны флуоресцентный и ближнепольный микроскопы.

В программу Школы вошел конкурс электронно-микроскопических изображений "Красота микро- и наномира", цель которого - популяризация методов микроскопии в различных научных сферах.

Информация о заседаниях и других мероприятиях Школы доступна в социальных сетях.

Обсуждения повестки в рамках круглого стола показали большую заинтересованность слушателей в проведении подобных встреч, причем высказаны пожелания расширить объем учебных занятий по классическим методам и методикам микроскопии, пригласив для чтения лекций известных Российских и зарубежных ученых.

Школа состоялась в основном благодаря финансовой поддержке Российского фонда фундаментальных исследований (грант № 18-32-10025), причем участие было бесплатным. Проживание в гостинице при Доме ученых РАН для молодых лекторов и слушателей Школы, оплата билетов участников из удаленных регионов выполнена из средств гранта.

\section{ИСКУССТВЕННЫЕ ГЛАЗА, ПОДСМОТРЕННЫЕ У НАСЕКОМЫХ}

Глаза млекопитающих имеют одну фокусирующую линзу и создают изображения высокой резкости. Фасеточные глаза насекомых состоят из тысяч оптических элементов и обеспечивают более широкий угол обзора, высокую светочув

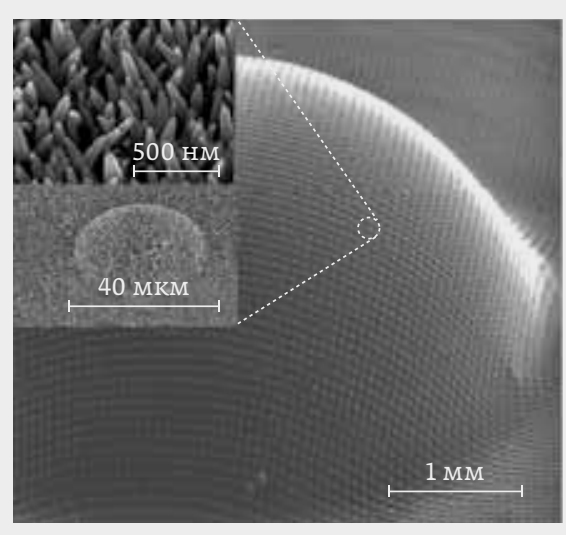

ствительность и фиксацию мельчайших движений. С помощью лазеров и нанотехнологии ученые пытаются воспроизвести природное устройство глаза насекомых для использова ния в автономных видеокамерах и роботах. В идеале искусственные глаза должны иметь выпуклую форму, на которой закрепляют светочувствительные датчики, низкое светоотражение и высокую гидрофобность. Китайские ученые предложили недорогой метод производства структурно-гомогенной основы искус ственных глаз.

Сначала исследователи нанесли выпу клости на тонкий двойной слой акрилового стекла: фемтосекундный лазер фокусировали на нижнем слое и облучали материал. Фотолиз акрила сопровождался выделением газов, которые формировали (“выдували») микроку- пола. Диаметр и высоту куполов контролировали, изменяя энергию лазера и длительность облучения. Затем форму стеклянной заготовки перенесли на полимерную мембрану, изогнули ее по форме глаза и отлили эпоксидную основу. В финале на микрокуполах основы вырастили кристаллы оксида цинка в форме трубочек. Плотность и высота трубочек зависела от времени выдержки в растворе нитрата цинка в гексаметилентетрамине. В результате ученые получили "глаз" размером в несколько миллиметров с выпуклостями диаметром 40-50 мкм, покрытыми нанокристаллами. Иерархичная структура обладает высокой оптической стабильностью, антиотражающими и водоотталкивающими свойствами.

ACS Nano, 2019. DOI: 10.1021/acsnano.8b04047 